\title{
Avaliação agronômica e econômica da aplicação de biossólido na produção de soja
}

\author{
Jorge Lemainski(1) e José Eurípedes da Silva(2)
}

(1)Embrapa Cerrados, BR 020, Km 18, Caixa Postal 08223, CEP 73301-970 Planaltina, DF. E-mail: jlemaisnski@hotmail.com (2)Embrapa Sede, Av. W3 Norte (final), Parque Estação Biológica, Caixa Postal 040315, CEP 70770-991 Brasília, DF. E-mail: joesilva@sede.embrapa.br

\begin{abstract}
Resumo - O objetivo deste trabalho foi definir parâmetros técnicos e econômicos do uso de biossólido como fertilizante para a soja. A resposta da soja à aplicação de biossólido úmido, nas doses $0,7,5,15,30 \mathrm{e}$ $45 \mathrm{Mg} \mathrm{ha}^{-1}$ foi comparada à resposta ao fertilizante mineral, aplicado em quantidades equivalentes de NPK, por dois anos de cultivo, em um Latossolo Vermelho distrófico argiloso. Utilizou-se o delineamento experimental de blocos ao acaso, com nove tratamentos e três repetições. Biossólido e fertilizante mineral foram aplicados somente antes do primeiro cultivo. Na dose de $30 \mathrm{Mg} \mathrm{ha}^{-1}$ de biossólido úmido, as produções de $3.602 \mathrm{e} 3.183 \mathrm{~kg} \mathrm{ha}^{-1} \mathrm{de}$ grãos, no primeiro e segundo cultivo, respectivamente, evidenciaram o efeito imediato e residual do material, o que também foi observado na dose de $45 \mathrm{Mg} \mathrm{ha}^{-1}$. Em termos econômicos, a melhor relação benefício-custo $(1,15)$ foi obtida na dose de $30 \mathrm{Mg} \mathrm{ha}^{-1}$. A eficiência agronômica dos tratamentos com biossólido, em média, foi $18 \%$ superior aos tratamentos com fertilizante mineral. Os resultados mostram a viabilidade agronômica e econômica do uso do biossólido em substituição ao fertilizante mineral, na produção de soja.
\end{abstract}

Termos para indexação: Glycine max, lodo de esgoto, nutrientes, fertilizante, análise econômica.

\section{Agronomic and economic evaluation of biosolid application on soybean production}

\begin{abstract}
The objective of this work was to define technical and economic parameters for biosolid use as fertilizer for soybean production. The soybean response to humid biosolid at rates $7.5,15,30$ and $45 \mathrm{Mg} \mathrm{ha}^{-1}$ was compared to equivalent NPK applied as mineral fertilizer, in two crop seasons in a Rhodic Haplustox. Nine treatments were arranged in a randomized block design with three repetitions. Biosolid and mineral fertilizer were incorporated at once before the first crop. At the rate of $30 \mathrm{Mg} \mathrm{ha}^{-1}$ of humid biosolid, grain yields of 3,602 and $3,183 \mathrm{~kg} \mathrm{ha}^{-1}$, in the first and second crops, respectively, showed the immediate and residual effects of biosolid application. The same trend was observed at $45 \mathrm{Mg} \mathrm{ha}^{-1}$ of biosolid. In economic terms, the best benefit-cost ratio (1.15) was obtained at $30 \mathrm{Mg} \mathrm{ha}^{-1}$. As for its agronomic fertilizer effect, biosolid was, in average, $18 \%$ more efficient than the mineral fertilizer. These results show the agronomic and economic viability of biosolid as a substitute of mineral fertilizer for soybean production.
\end{abstract}

Index terms: Glycine max, sewage sludge, nutrients, fertilizer, economic evaluation.

\section{Introdução}

O biossólido úmido, resíduo do tratamento de esgotos, é gerado pela Companhia de Saneamento Ambiental do Distrito Federal (Caesb) à razão de $400 \mathrm{t} \mathrm{dia}^{-1}$. Por ser rico em matéria orgânica e nutrientes minerais, principalmente $\mathrm{N}$ e $\mathrm{P}$, pode ser aproveitado em áreas agrícolas como fertilizante ou como condicionador de solo, depois de adequadamente tratado (Melo et al., 2001). Apesar da carência de critérios locais para uso agronômico, o material é demandado como fertilizante na produção de grãos, pastagens, fruteiras e café.
Os Estados Unidos e a Europa produzem, respectivamente, cerca de 13 milhões e 7 milhões de toneladas de biossólidos, base seca, por ano, com rotas respectivas de disposição final em aterros $(41 \%$ e $42 \%)$, uso agrícola ( $25 \%$ e $36 \%)$, incineração ( $16 \%$ e $11 \%)$, disposição oceânica ( $6 \%$ e $5 \%)$, e outras formas como em reflorestamento e recomposição de áreas degradadas em 12\% e 6\% (Tsutiya, 2001). No Brasil, a produção de biossólido, base seca, é estimada em 202.530 t anuais, a partir do tratamento do esgoto gerado por 16,8 milhões de pessoas, conforme diagnóstico dos serviços de água e esgoto, em 2004 (Brasil, 2005), e a produção estimada é 
de $33 \mathrm{~g}$ de sólidos solúveis totais por habitante por dia (Machado et al., 2004). Do lodo produzido no Brasil, cerca de 50\% tem destino final em aterro sanitário, 15\% na agricultura e 35\% têm destino indefinido; acredita-se que grande parte é depositada em aterro sanitário (Machado et al., 2004).

No Distrito Federal, com uma população de 2,3 milhões de habitantes, a coleta de esgotos, de origem predominantemente doméstica, atinge $88 \%$ da população; o índice de coleta de esgoto é de $71,8 \%$ e o de tratamento é de 75,4\% (Brasil, 2005).

A área agrícola do Distrito Federal é de 163 mil hectares em lavouras e pastagens, conforme o último Censo Agropecuário (IBGE, 2006). Grande parte dessa área tem relevo plano, solos profundos e bem drenados e apresenta aptidão à reciclagem agrícola do biossólido.

Experiências com uso de biossólido demonstraram seus benefícios para diversas culturas e para algumas características químicas e propriedades físicas do solo (Berton et al., 1989; Melo et al., 1994, 2001; Oliveira et al., 2002).

Da Ros et al. (1993) avaliaram o efeito imediato da aplicação do biossólido em milheto e o efeito residual na associação aveia-ervilhaca; Gadioli \& Neto (2004) avaliaram o efeito do biossólido em milho e feijão; Corrêa (2004) estimou a eficiência de cinco biossólidos em suprir $\mathrm{N}$ e P para azevém; Guedes et al. (2006) avaliaram as propriedades químicas do solo e a nutrição do eucalipto, em conseqüência da aplicação de lodo de esgoto.

No Distrito Federal, Silva et al. (2002a, 2002b) utilizaram doses de biossólido úmido de 54 a $216 \mathrm{Mg} \mathrm{ha}^{-1}$, na produção de milho, e sugeriram que doses menores poderiam apresentar melhor resultado prático e econômico. Em Jaguariúna, SP, Vieira et al. (2005) avaliaram o efeito da aplicação de biossólido em dois cultivos de soja e verificaram que as necessidades de $\mathrm{P}$ da cultura podem ser supridas pela adição de pequenas quantidades do material ao solo, no primeiro cultivo, sem prejuízo para a produção ou qualidade dos grãos. Apesar dessa referência, são poucos os trabalhos com soja citados na literatura. Uma provável explicação deve-se à fixação do $\mathrm{N}$ atmosférico pelas leguminosas (soja, feijão), o que reduz sua dependência dos fertilizantes nitrogenados, enquanto as gramíneas (milho, trigo, canade-açúcar, milheto, sorgo), por dependerem do fertilizante nitrogenado, respondem com maior intensidade ao biossólido, tirando proveito da liberação lenta do $\mathrm{N}$ do material (Sanepar, 1997).
O objetivo deste trabalho foi definir, num Latossolo Vermelho distrófico argiloso, parâmetros técnicos e econômicos de resposta da soja à aplicação de biossólido úmido, em comparação ao uso de fertilizante mineral em doses equivalentes de NPK.

\section{Material e Métodos}

O trabalho foi realizado em dois anos agrícolas, no período de 2001 a 2003, na Embrapa Cerrados, Planaltina, DF, num Latossolo Vermelho distrófico argiloso (520 $\mathrm{g} \mathrm{kg}^{-1} \mathrm{de}$ argila). A área experimental $\left(15^{\circ} 35^{\prime} 41^{\prime \prime} \mathrm{S} ; 47^{\circ} 43^{\prime} 44^{\prime \prime} \mathrm{W}\right)$ foi utilizada no final da década de 70 para teste de híbridos de milho, posteriormente foi cultivada com capim Brachiaria sp. e encontrava-se em pousio há mais de oito anos. A Estação Principal da Embrapa Cerrados (15\%35'30"S; $47^{\circ} 42^{\prime} 30^{\prime \prime} \mathrm{W}$; altitude $1.007 \mathrm{~m}$ ), próxima ao local do experimento, registrou precipitações de $888,3 \mathrm{~mm}$ de chuva, entre novembro de 2001 e março de 2002 , e de $772,2 \mathrm{~mm}$ entre novembro de 2002 e março de 2003, períodos em que foram realizados os experimentos.

A análise do solo (Embrapa, 1997) em amostras coletadas antes da semeadura, na camada de $0-20 \mathrm{~cm}$, indicou: $\mathrm{pH}$ em água 5,17; $\mathrm{Al} 1,5 \mathrm{mmol}_{\mathrm{c}} \mathrm{dm}^{-3} ; \mathrm{H}+\mathrm{Al}$ 41,9 mmol $_{\mathrm{c}} \mathrm{dm}^{-3} ; \mathrm{Ca}+\mathrm{Mg} 30,4 \mathrm{mmol}_{\mathrm{c}} \mathrm{dm}^{-3} ; \mathrm{K} 46,8 \mathrm{mg} \mathrm{dm}^{-3}$; V 39,25\%; P 3,35 mg dm $\mathrm{mo}^{-3}$ MO 25,3 $\mathrm{g} \mathrm{dm}^{-3}$.

O biossólido foi fornecido pela Estação de Tratamento de Esgotos Brasília Norte, da Companhia de Saneamento Ambiental do Distrito Federal (Caesb), em outubro de 2001, após processo de estabilização biológica (anaeróbia e aeróbia), seguido de polimento final com aplicação de coagulante metálico (Luduvice, 2000).

A caracterização química do material (Tabela 1) foi realizada em oito amostras compostas, cada uma constituída de dez subamostras (Soccol et al., 2000). Avaliaram-se a densidade do biossólido úmido (volume e peso iniciais das amostras recém-coletadas) e a do material seco (volume e peso finais das amostras, após secagem em estufa a $65^{\circ} \mathrm{C}$, por 72 horas, e depois a $105^{\circ} \mathrm{C}$, até atingir peso constante).

$\mathrm{O}$ experimento foi estruturado em delineamento de blocos ao acaso, com três repetições e nove tratamentos (Tabela 2). As fontes de N, P e K foram, respectivamente, uréia $\left(0,44 \mathrm{~kg} \mathrm{de} \mathrm{N} \mathrm{kg}^{-1}\right)$, superfosfato triplo $\left(0,184 \mathrm{~kg} \mathrm{de} \mathrm{P} \mathrm{kg}^{-1}\right)$ e cloreto de potássio $(0,498 \mathrm{~kg}$ de $\left.\mathrm{K} \mathrm{kg}^{-1}\right)$. $\mathrm{O}$ cálculo da dose equivalente do fertilizante mineral misto foi realizado com base na análise química, densidade e teor de água do biossólido. O biossólido e o 
fertilizante mineral aplicados a lanço, em única vez, em 14 de novembro de 2001, foram imediatamente incorporados ao solo com grade niveladora, à profundidade de $10 \mathrm{~cm}$.

A dimensão de cada parcela era de 9x7 m e a área útil de $10,8 \mathrm{~m}^{2}$. A primeira semeadura da soja, cultivar BRS Milena, ocorreu em 16 de novembro de 2001, em solo preparado no sistema convencional (arado de discos e grade). A segunda semeadura, cultivar BRS Pétala, foi realizada em 20 de novembro de 2002, no sistema de plantio direto, sem adição de biossólido ou fertilizante mineral. Nos dois cultivos, realizou-se semeadura mecanizada, com espaçamento de $45 \mathrm{~cm}$ entre linhas e densidade populacional de 320 mil plantas por hectare. Durante o desenvolvimento da cultura, foram realizados os tratos culturais de rotina para o controle de pragas e de plantas invasoras.

As colheitas dos dois cultivos ocorreram em 4 e 18 de abril de 2002 e 2003 , respectivamente, na área útil de $10,8 \mathrm{~m}^{2}$ (seis linhas de $4 \mathrm{~m}$ lineares) de cada parcela. Os grãos foram separados e os restos culturais devolvidos à respectiva parcela. A produtividade de grãos foi estimada, tendo-se ajustado a umidade dos grãos para 13\%.

O SAS Institute (2001) foi utilizado na análise de variância e no ajuste de regressões polinomiais, relacionando-se a produção de grãos com doses de biossólido e de fertilizante mineral. Também foram utilizados contrastes não-ortogonais, para comparação entre os resultados obtidos com biossólido e com fertilizante mineral.

Para as avaliações econômicas, simulou-se uma propriedade distante $100 \mathrm{~km}$ da ETE-Brasília Norte da Caesb, em condições semelhantes às da área experimental, quando da aplicação do biossólido e do fertilizante mineral. Todos os cálculos foram ajustados para a unidade de área de um hectare.

A receita bruta para cada tratamento foi obtida mediante a multiplicação do somatório da produtividade de grãos do primeiro e do segundo cultivo pelo preço pago ao produtor ( $\mathrm{R} \$ 29,99$ por saca de $60 \mathrm{~kg}$ ), conforme Conab (2003).

Tabela 1. Caracterização química do biossólido fornecido pela Companhia de Saneamento Ambiental do Distrito Federal (Caesb).

\begin{tabular}{lccc}
\hline Característica & $\mathrm{Caesb}^{(1)}$ & CPAC & IAC $^{(3)}$ \\
\hline Teor de água $\left(\mathrm{g} \mathrm{kg}^{-1}\right)$ & $820-860$ & $930-810$ & - \\
Matéria orgânica $\left(\mathrm{g} \mathrm{kg}^{-1}\right)$ & $600-630$ & $634,5-656,9$ & $473,6-568,2$ \\
Cinzas $\left(\mathrm{g} \mathrm{kg}^{-1}\right)$ & $350-400$ & $32,31-35,28$ & - \\
$\mathrm{pH}$ & $5,6-8,1$ & $5,8-7,4$ & - \\
$\mathrm{N}\left(\mathrm{g} \mathrm{kg}^{-1}\right)$ & $10-50$ & $51,8-56,9$ & $41,2-53,3$ \\
$\mathrm{P}\left(\mathrm{g} \mathrm{kg}^{-1}\right)$ & $20-40$ & $32,4-37,4$ & $30,9-37,1$ \\
$\mathrm{~K}\left(\mathrm{~g} \mathrm{~kg}^{-1}\right)$ & $5-10$ & $2,9-4,0$ & $3,5-4,5$ \\
$\mathrm{Ca}\left(\mathrm{g} \mathrm{kg}^{-1}\right)$ & $10-12$ & $13,3-16,7$ & $15,9-26,7$ \\
$\mathrm{~S}\left(\mathrm{~g} \mathrm{~kg}^{-1}\right)$ & $8,2-12,2$ & $8,2-9,4$ & $9,3-9,6$ \\
$\mathrm{Mg}\left(\mathrm{g} \mathrm{kg}^{-1}\right)$ & $3-5$ & $6,3-6,8$ & $6,7-7,1$ \\
$\mathrm{~B}\left(\mathrm{mg} \mathrm{kg}^{-1}\right)$ & - & $13,0-26,1$ & $13,6-17,1$ \\
$\mathrm{Co}\left(\mathrm{mg} \mathrm{kg}^{-1}\right)$ & $<1$ & - & - \\
$\mathrm{Cu}\left(\mathrm{mg} \mathrm{kg}^{-1}\right)$ & $70-85$ & $126,0-243,0$ & $138,4-155,6$ \\
$\mathrm{Fe}\left(\mathrm{mg} \mathrm{kg}^{-1}\right)$ & $9.000-11.000$ & $22.150,0-24.390,0$ & $23.685,0-26.161,0$ \\
$\mathrm{Mn}\left(\mathrm{mg} \mathrm{kg}^{-1}\right)$ & $79-81$ & $83,1-124,1$ & $116,5-138,4$ \\
$\mathrm{Mo}\left(\mathrm{mg} \mathrm{kg}^{-1}\right)$ & - & - & $<0,1$ \\
$\mathrm{Na}\left(\mathrm{mg} \mathrm{kg}^{-1}\right)$ & - & $610,9-816,0$ & $700,0-900,0$ \\
$\mathrm{Zn}\left(\mathrm{mg} \mathrm{kg}^{-1}\right)$ & $320-350$ & $676,5-732,6$ & $593,6-623,8$ \\
$\mathrm{Al}\left(\mathrm{mg} \mathrm{kg}^{-1}\right)$ & $10.000-12.000$ & $36.220,0-45.400,0$ & $43.269,0-53.003,0$ \\
$\mathrm{As}\left(\mathrm{mg} \mathrm{kg}^{-1}\right)$ & - & - & $<0,1$ \\
$\mathrm{Cd}\left(\mathrm{mg} \mathrm{kg}^{-1}\right)$ & $<2$ & - & $2,3-2,5$ \\
$\mathrm{~Pb}\left(\mathrm{mg} \mathrm{kg}^{-1}\right)$ & 50 & - & $90,4-95,6$ \\
$\mathrm{Cr}\left(\mathrm{mg} \mathrm{kg}^{-1}\right)$ & $48-56$ & - & $33,2-39,6$ \\
$\mathrm{Hg}\left(\mathrm{mg} \mathrm{kg}^{-1}\right)$ & 4 & - & $<0,1$ \\
$\mathrm{Ni}\left(\mathrm{mg} \mathrm{kg}^{-1}\right)$ & $2,5-5,2$ & - & $12,7-19,1$ \\
$\mathrm{Se}\left(\mathrm{mg} \mathrm{kg}^{-1}\right)$ & - & - & $<0,1$ \\
\hline
\end{tabular}

${ }^{(1)}$ Adaptado de Silva et al. (2002a), teores em base seca. (2)Embrapa Cerrados (biossólido seco, utilizado no experimento; teor de água: $100 \mathrm{~g} \mathrm{~kg}{ }^{-1}$; média de seis amostras). ${ }^{(3)}$ Instituto Agronômico, Campinas, SP (biossólido seco; teor de água: $100 \mathrm{~g} \mathrm{~kg}^{-1}$; média de duas amostras). 
O custo de produção da lavoura comercial de soja, para ambos os cultivos, foi estabelecido a partir de orçamento analítico.Na matriz de custos, o valor dos fertilizantes (biossólido e fertilizante mineral) foi definido isoladamente para cada tratamento. Assim, o custo de 1 ha de soja, excluindo-se os fertilizantes, foi orçado em $\mathrm{R} \$ 580,00$, dos quais: $\mathrm{R} \$ 366,00$ em insumos (sementes, fungicidas, herbicidas, inseticidas, adjuvantes) e R $\$ 214,00$ em serviços (preparo do solo, plantio, aplicação de insumos, transportes internos, colheita, mão-de-obra contratada e assistência técnica). Para cada tratamento, o custo de produção correspondeu ao valor do fertilizante utilizado (mineral ou biossólido), somado ao valor dos insumos e serviços.

O custo do fertilizante mineral, por tratamento, foi calculado pelo valor de $\mathrm{N}, \mathrm{P}$ e $\mathrm{K}$ e a respectiva quantidade aplicada. De acordo com pesquisa de preço pago pelo produtor (Conab, 2003), a cotação da tonelada de produto, posto na propriedade a $100 \mathrm{~km}$, referenciada em abril de 2003, foi: uréia, $\mathrm{R} \$ 845,00$; superfosfato triplo, $\mathrm{R} \$ 819,00$; e cloreto de potássio, R\$666,00.

O custo do biossólido por tratamento foi equivalente à dose aplicada $\left(\mathrm{Mg} \mathrm{ha}^{-1}\right)$, multiplicada pelo frete de $\mathrm{R} \$ 22,00$ por tonelada (no Distrito Federal, o frete para a distância média de transporte de $100 \mathrm{~km}$, com caminhão-caçamba de $12 \mathrm{~m}^{3}$, com

Tabela 2. Doses de biossólido $\left(\mathrm{t} \mathrm{ha}^{-1}\right)$ e de fertilizante mineral $\left(\mathrm{kg} \mathrm{ha}^{-1}\right)$ aplicadas no cultivo de soja em solo do Cerrado.

\begin{tabular}{lcr}
\hline Tratamento $^{(1)}$ & Doses $^{(2)}$ & $\begin{array}{c}\text { Teor de NPK } \\
\left(\mathrm{kg} \mathrm{ha}^{-1}\right)\end{array}$ \\
\hline 1. Testemunha & 0,0 & $00-00-00$ \\
2. BSL1 & 7,5 & $44-31-03$ \\
3. BSL2 & 15,0 & $88-62-07$ \\
4. BSL3 & 30,0 & $176-124-13$ \\
5. BSL4 & 45,0 & $264-186-20$ \\
6. FMN1 & $100-168-07$ & $44-31-03$ \\
7. FMN2 & $200-337-14$ & $88-62-07$ \\
8. FMN3 & $400-674-26$ & $176-124-13$ \\
9. FMN4 & $600-1.011-40$ & $264-186-20$ \\
\hline
\end{tabular}

(1)BSL: biossólido; FMN: fertilizante mineral. (2)BSL: teor de água de $900 \mathrm{~g} \mathrm{~kg}^{-1} \mathrm{e}$ densidade de $0,964 \mathrm{~kg} \mathrm{~L}^{-1} ; \mathrm{FMN}$ : uréia $\left(0,44 \mathrm{~kg} \mathrm{~kg}^{-1} \mathrm{de} \mathrm{N}\right)$, superfosfato triplo $\left(0,184 \mathrm{~kg} \mathrm{~kg}^{-1}\right.$ de $\left.\mathrm{P}\right)$ e cloreto de potássio $\left(0,498 \mathrm{~kg} \mathrm{~kg}^{-1}\right.$ de $\left.\mathrm{K}\right)$. (3) Análise química do biossólido seco (teor de água de $100 \mathrm{~g} \mathrm{~kg}^{-1}$ ): $\mathrm{N} 53,27 \mathrm{~g} \mathrm{~kg}^{-1}$; $37,37 \mathrm{~g} \mathrm{~kg}^{-1}$; $\mathrm{K} 3,98 \mathrm{~g} \mathrm{~kg}^{-1}$. capacidade para 10 t de biossólido, é de $\mathrm{R} \$ 1,10$ por quilômetro rodado); àquele valor foi adicionado o custo de distribuição do biossólido ( $\left.\mathrm{R} \$ 24,00 \mathrm{ha}^{-1}\right) \mathrm{e}$ de incorporação ( $\mathrm{R} \$ 20,00 \mathrm{ha}^{-1}$ ), conforme Canziani et al. (2001). O biossólido é fornecido gratuitamente.

$\mathrm{Na}$ análise de benefício-custo, do uso do biossólido como fertilizante (Silva et al., 2002b), foram utilizadas as receitas de comercialização, considerando-se a produtividade de grãos, obtida na área experimental, e os custos de produção nas lavouras comerciais de soja, no Distrito Federal, com base nos preços praticados em abril de 2003. Aplicou-se a equação: $\mathrm{BC}=(\mathrm{RP}-\mathrm{RT}) / \mathrm{CP}$, em que $\mathrm{BC}$ é a relação benefíciocusto; RP é a receita bruta da produção de cada tratamento; RT é a receita bruta do tratamento testemunha e CP é o custo de produção de cada tratamento.

A eficiência agronômica (valor fertilizante) do biossólido (EB), em relação ao fertilizante mineral (Silva et al., 2002a), foi obtida pela equação: $\mathrm{EB}=100(\mathrm{~PB}-\mathrm{PT}) /(\mathrm{PF}-\mathrm{PT})$, em que $\mathrm{PB}$ é a produtividade de grãos nos tratamentos com biossólido; PT é a produtividade do tratamento testemunha; e, PF é a produtividade dos tratamentos com fertilizante mineral. A eficiência nos tratamentos 2 , 3, 4 e 5, com uso de biossólido úmido, foi determinada tomando-se como referência, respectivamente, os tratamentos 6, 7, 8 e 9, que utilizaram fertilizante mineral em doses de NPK equivalentes às aplicadas nos tratamentos com biossólido.

A valoração do biossólido foi definida a partir do preço do fertilizante mineral, com base no mercado de bens substitutos, utilizando-se o método do custo de reposição sugerido por Motta (1998). O valor da tonelada de biossólido foi determinado para o material com teor de água de $900 \mathrm{~g} \mathrm{~kg}^{-1}$. A agregação de valor ao biossólido foi também simulada para o produto desidratado, com teores de água de 850, 700, 500 e $300 \mathrm{~g} \mathrm{~kg}^{-1}$, a partir de coeficientes de redução de massa e volume estabelecidos por Silva et al. (2002b).

Para efeitos de referência de conversão de moedas, o dólar norte-americano foi cotado a três reais (US\$1,00 $=\mathrm{R} \$ 3,00)$.

\section{Resultados e Discussão}

A análise comparativa mostrou que a produtividade de todos os tratamentos foi significativamente superior à da testemunha (Tabela 3 ). Os resultados da análise 
de contrastes não-ortogonais mostraram que a produtividade média da soja, obtida com biossólido, foi estatisticamente superior à obtida com fertilizante mineral em $6 \%$, no primeiro cultivo (F 11,82; $>>0,0034$ ), e $10 \%$ no segundo (F 13,66: $\mathrm{p}>0,0020$ ); na média dos dois cultivos, a produtividade com biossólido foi $8 \%$ superior à do fertilizante mineral (F 52,43; p>0,0001). Provavelmente, o melhor resultado do biossólido possa ser atribuído à liberação gradativa dos nutrientes, principalmente o P; segundo Melo et al. (2001), o P do biossólido é menos solúvel no solo que o dos superfosfatos, mas oferece maior constância no fornecimento ao longo do tempo.

Por ser uma leguminosa capaz de fixar o $\mathrm{N}$ atmosférico, quando em associação simbiótica com bactérias do gênero Bradyrhizobium, a soja parece ter como aporte mineral mais expressivo do biossólido o $\mathrm{P}$, o que está em conformidade com Sanepar (1997). A produtividade da soja, nos dois anos agrícolas, demonstrou que tanto a dose de $30 \mathrm{Mg} \mathrm{ha}^{-1}$ quanto a de $45 \mathrm{Mg} \mathrm{ha}^{-1}$ de biossólido foi suficiente para suprir as demandas da cultura em $\mathrm{P}$, o que também foi observado

Tabela 3. Efeito do biossólido na produtividade de grãos dos dois cultivos de $\operatorname{soja}^{(1)}$.

\begin{tabular}{|c|c|c|c|}
\hline Tratamento & $\begin{array}{l}\text { Primeiro } \\
\text { cultivo }\end{array}$ & $\begin{array}{l}\text { Segundo } \\
\text { cultivo }\end{array}$ & Médias \\
\hline & \multicolumn{3}{|c|}{ 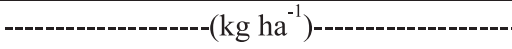 } \\
\hline Testemunha & $1.651,5 \mathrm{f}$ & $841,9 f$ & $1.246,7 \mathrm{e}$ \\
\hline BSL1 & $2.626,5 \mathrm{de}$ & $1.726,8 \mathrm{de}$ & $2.176,7 d$ \\
\hline BSL2 & $3.087,0 \mathrm{bc}$ & $2.299,1 \mathrm{c}$ & $2.693,1 \mathrm{c}$ \\
\hline BSL3 & $3.602,2 \mathrm{a}$ & $3.183,0 \mathrm{ab}$ & $3.392,6 a$ \\
\hline BSL4 & $3.463,9 \mathrm{ab}$ & $3.448,3 \mathrm{a}$ & $3.456,1 \mathrm{a}$ \\
\hline FMN1 & $2.516,9 \mathrm{e}$ & $1.522,4 \mathrm{e}$ & $2.019,7 \mathrm{~d}$ \\
\hline FMN2 & $2.937,6 \mathrm{~cd}$ & $2.032,9 \mathrm{~cd}$ & $2.485,3 \mathrm{c}$ \\
\hline FMN3 & $3.402,5 \mathrm{ab}$ & $2.922,9 \mathrm{~b}$ & $3.162,9 \mathrm{~b}$ \\
\hline FMN4 & $3.163,2 \mathrm{bc}$ & $3.128,2 \mathrm{~b}$ & $3.145,7 b$ \\
\hline CV (\%) & 4,6 & 4,5 & 2,9 \\
\hline
\end{tabular}

(1)Médias seguidas por letras iguais, na coluna, não diferem entre si a $5 \%$ de probabilidade pelo teste de Tukey. por Vieira et al. (2005). No caso do biossólido, no primeiro cultivo, a produtividade aumentou, significativamente, até a dose de $30 \mathrm{Mg} \mathrm{ha}^{-1}\left(3.602,2 \mathrm{~kg} \mathrm{ha}^{-1}\right)$, que não diferiu estatisticamente da dose de $45 \mathrm{Mg} \mathrm{ha}^{-1}\left(3.463,9 \mathrm{~kg} \mathrm{ha}^{-1}\right)$. No segundo cultivo, houve aumento crescente de produtividade até a dose de $45 \mathrm{Mg} \mathrm{ha}^{-1}$, que atingiu $3.448,3 \mathrm{~kg} \mathrm{ha}^{-1}$ de grãos.

Embora produções de parcelas não sejam comparáveis com produções de campo, observa-se que as médias de produtividade dos dois cultivos, dos tratamentos que utilizaram $30 \mathrm{Mg} \mathrm{ha}^{-1}$ e $45 \mathrm{Mg} \mathrm{ha}^{-1} \mathrm{de}$ biossólido úmido, superaram em $23 \%$ a produtividade média (2.769 $\left.\mathrm{kg} \mathrm{ha}^{-1}\right)$ da soja no Distrito Federal, e em $21 \%$ o rendimento médio $\left(2.802 \mathrm{~kg} \mathrm{ha}^{-1}\right)$ da cultura no Brasil em 2003, segundo o IBGE.

As médias de produtividade nas doses de 30 e $45 \mathrm{Mg} \mathrm{ha}^{-1}$ de bissólido úmido, no segundo cultivo, corresponderam, respectivamente, a $88 \%$ e $99 \%$ das obtidas no primeiro cultivo, o que evidencia o efeito residual da aplicação do biossólido. Vieira et al. (2005), em experimento com aplicação única de $3 \mathrm{Mg} \mathrm{ha}^{-1}$ de biossólido, base seca (aproximadamente $30 \mathrm{Mg} \mathrm{ha}^{-1}$, base úmida), no primeiro cultivo, obtiveram a produtividade de $3.099 \mathrm{~kg} \mathrm{ha}^{-1}$ de soja no segundo cultivo. Este resultado é semelhante ao obtido neste trabalho (3.183 $\mathrm{kg} \mathrm{ha}^{-1}$ ), por ocasião do segundo cultivo (com a aplicação de $30 \mathrm{Mg} \mathrm{ha}^{-1}$ de biossólido úmido no primeiro cultivo), e ambos evidenciaram o efeito residual do biossólido na cultura da soja.

O modelo de regressão polinomial de segundo grau, ajustado aos dados de produtividade, representou adequadamente as respostas da soja às doses de biossólido úmido e fertilizante mineral (Tabela 4). A derivação daquelas equações mostrou que a produtividade máxima estimada de grãos $\left(3.685 \mathrm{~kg} \mathrm{ha}^{-1}\right)$, no primeiro ano, seria atingida com $33,2 \mathrm{Mg} \mathrm{ha}^{-1}$ de biossólido úmido, enquanto no segundo ano (efeito

Tabela 4. Relação entre a produtividade de grãos de soja (y), no primeiro e no segundo cultivo, e as doses de biossólido e fertilizante mineral (x) aplicadas ao solo.

\begin{tabular}{lcc}
\hline Insumo & Equações & $\mathrm{R}^{2}$ \\
\hline & Primeiro cultivo & $0,9905^{* *}$ \\
Biossólido & $\mathrm{y}=-1,7811^{* *} \mathrm{x}^{2}+118,28^{* *} \mathrm{x}+1721,8^{* *}$ & $0,9933^{* *}$ \\
\hline Fertilizante mineral & $\mathrm{y}=-1,7201 * * \mathrm{x}^{2}+109,53 * * \mathrm{x}+1701,5^{* *}$ & Segundo cultivo \\
\hline & $\mathrm{y}=-1,3394 * \mathrm{x}^{2}+117,57 * * \mathrm{x}+866,09 * *$ & $0,999 * *$ \\
Biossólido & $\mathrm{y}=-1,0960^{* *} \mathrm{x}^{2}+100,94 * * \mathrm{x}+824,11 * *$ & $0,998^{* *}$ \\
\hline
\end{tabular}

**Significativo a $1 \%$ de probabilidade. 
residual), a máxima produtividade (3.446 $\left.\mathrm{kg} \mathrm{ha}^{-1}\right)$ seria alcançada com 43,89 $\mathrm{Mg} \mathrm{ha}^{-1}$ de biossólido úmido. O aumento na dose, para a máxima produtividade, é apenas aparente e pode ser explicado pelo fato de que a regressão do segundo ano foi obtida com os valores nominais das doses do primeiro cultivo, sem os descontos causados pela remoção de nutrientes do solo, na primeira colheita, o que reduz as quantidades disponíveis para as plantas na safra seguinte.

A produtividade da soja (média dos dois anos), em resposta às doses de biossólido (Figura 1), mostra que, com base na equação de ajuste, a produtividade máxima estimada em grãos $\left(3.522 \mathrm{~kg} \mathrm{ha}^{-1}\right)$ seria atingida com $37,79 \mathrm{Mg} \mathrm{ha}^{-1}$ de biossólido úmido.

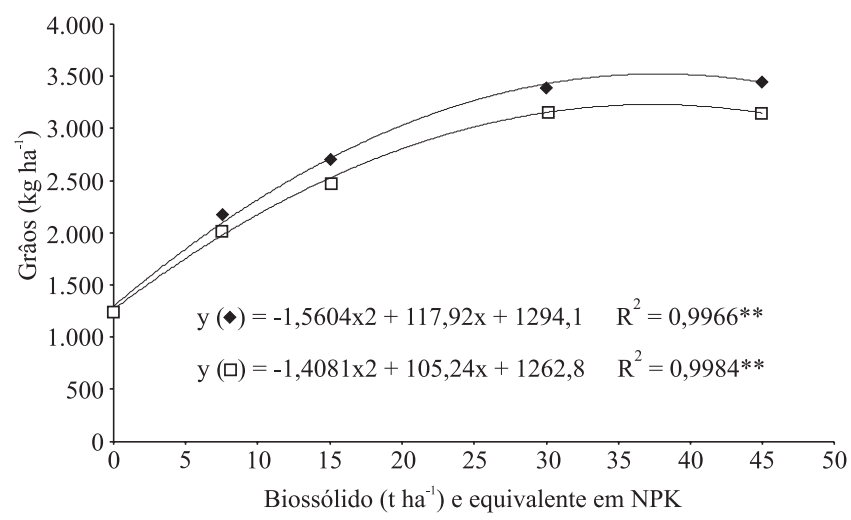

Figura 1. Efeito do biossólido $(\bullet)$ e do fertilizante mineral ( $\square$ ) na produtividade de grãos de soja. Média dos dois cultivos.
A análise de benefício-custo (Tabela 5) mostra a taxa de retorno de cada real aplicado no biossólido e no fertilizante mineral. Assim, em relação à lavoura comercial proposta, os resultados de produtividade da soja indicaram que, nos tratamentos com uso de biossólido (exceto o que recebeu 7,5 $\mathrm{Mg} \mathrm{ha}^{-1}$ ), a taxa de retorno foi maior do que a verificada em qualquer um dos tratamentos com fertilizante mineral. Esse resultado pode ser atribuído ao aumento da receita obtida pela maior produtividade, como também, ao menor custo de produção, resultante da utilização do biossólido, em relação ao fertilizante mineral. A aplicação de $30 \mathrm{Mg} \mathrm{ha}^{-1}$ de biossólido úmido proporcionou a melhor taxa de retorno, entre todos os tratamentos (R\$1,15 para cada real investido).

$\mathrm{Na}$ lavoura comercial, na qual a fixação biológica do $\mathrm{N}$ atmosférico pela soja dispensa a aplicação desse nutriente como adubo (Vargas et al., 2002), a análise de benefício-custo no tratamento 8 (NPK 176-124-13), com a exclusão do custo do $\mathrm{N}$, apresentaria para cada real investido um retorno de $\mathrm{R} \$ 1,11$, ainda abaixo do retorno obtido com o tratamento 4 (30 $\mathrm{Mg} \mathrm{ha}^{-1}$ de biossólido úmido), equivalente ao tratamento 8 .

O mesmo retorno econômico, obtido com a aplicação de $30 \mathrm{Mg} \mathrm{ha}^{-1}$ de biossólido úmido ( $\mathrm{R} \$ 1,15$ por real investido), foi encontrado quando se simulou a relação de benefício-custo de uma lavoura de soja no Distrito Federal, que recebe uma adubação de manutenção de $60 \mathrm{~kg} \mathrm{ha}^{-1}$ de $\mathrm{P}_{2} \mathrm{O}_{5}(26,22 \mathrm{~kg}$ de $\mathrm{P}) \mathrm{e}$ $60 \mathrm{~kg} \mathrm{ha}^{-1}$ de $\mathrm{K}_{2} \mathrm{O}(49,8 \mathrm{~kg}$ de $\mathrm{K})$, para uma expectativa de produção de $3.000 \mathrm{~kg} \mathrm{ha}^{-1}$ de grãos de soja (Sousa \& Lobato, 2002).

Tabela 5. Análise de benefício-custo (BC) do biossólido e fertilizante mineral, em relação ao total de grãos dos dois cultivos de soja.

\begin{tabular}{|c|c|c|c|c|}
\hline Tratamento & $\begin{array}{c}\text { Produção total }^{(1)} \\
(\mathrm{kg})\end{array}$ & $\begin{array}{c}\text { Receita bruta } \\
(\mathrm{R} \$)\end{array}$ & $\begin{array}{c}\text { Custo de produção } \\
\left(\mathrm{R} \$ \mathrm{ha}^{-1}\right)\end{array}$ & $\begin{array}{c}\text { Relação } \\
\text { benefício/custo }^{(4)}\end{array}$ \\
\hline Testemunha & $2.493,4$ & $1.246,20$ & $1.160,00$ & - \\
\hline BSL1 & $4.353,3$ & $2.175,78$ & $1.369,00$ & 0,68 \\
\hline BSL2 & $5.386,1$ & $2.691,97$ & $1.534,00$ & 0,94 \\
\hline BSL3 & $6.785,2$ & $3.391,24$ & $1.864,00$ & 1,15 \\
\hline BSL4 & $6.912,2$ & $3.454,72$ & $2.194,00$ & 1,01 \\
\hline FM1 & $4.039,3$ & $2.018,84$ & $1.386,50$ & 0,56 \\
\hline FM2 & $4.970,1$ & $2.484,06$ & $1.614,33$ & 0,77 \\
\hline FM3 & $6.325,4$ & $3.161,43$ & $2.067,33$ & 0,93 \\
\hline FM4 & $6.291,4$ & $3.144,44$ & $2.523,58$ & 0,75 \\
\hline
\end{tabular}

${ }^{(1)}$ Somatório da produtividade por hectare de grãos do primeiro e do segundo cultivo. (2)Produção comercializada ao preço de R\$29,99 por saca de $60 \mathrm{~kg}$ (base abril 2003). ${ }^{(3)}$ Custo de insumos e serviços $(\mathrm{R} \$ 580,00)$ para cada ano, mais o valor dos fertilizantes por tratamento. ${ }^{(4)} \mathrm{BC}=(\mathrm{RP}-\mathrm{RT}) / \mathrm{CP}$, em que RP é a receita da produção, RT é a receita da testemunha e CP é o custo de produção. 
A análise da eficiência agronômica (Tabela 6) mostrou que no primeiro e no segundo cultivo o biossólido foi 15 e $20 \%$, respectivamente, mais eficiente que o fertilizante mineral, seguindo a mesma tendência observada por Silva et al. (2002a). $\mathrm{Na}$ avaliação da produtividade média dos dois cultivos, o biossólido foi $18 \%$ mais eficiente do que o fertilizante mineral. Considerando-se que os nutrientes foram adicionados em quantidades equivalentes, a superioridade do biossólido, em relação ao fertilizante mineral, pode ser atribuída à dinâmica de liberação dos nutrientes, principalmente do P, a partir das duas fontes (Melo et al., 2001).

O valor do biossólido úmido da Caesb foi de $\mathrm{R} \$ 30,44$ por tonelada, quando se considerou, exclusivamente, o custo de reposição do N, P e K, nas condições do presente trabalho (Motta, 1998). A elevada quantidade de água contida no biossólido é determinante desse valor relativamente baixo.

Tabela 6. Eficiência do biossólido (\%) como fornecedor de nitrogênio, fósforo e potássio para dois cultivos de soja ${ }^{(1)}$.

\begin{tabular}{lccc}
\hline Tratamento & Primeiro cultivo & Segundo cultivo & Média \\
\hline BSL1 & 113,3 & 130,2 & 121,7 \\
BSL2 & 111,4 & 123,1 & 117,3 \\
BSL3 & 113,9 & 113,4 & 113,6 \\
BSL4 & 120,6 & 114,2 & 117,4 \\
\hline Média & 114,8 & 120,2 & 117,5 \\
\hline
\end{tabular}

${ }^{(1)} \mathrm{A}$ eficiência do biossólido foi calculada pela equação: $\mathrm{EB}=100(\mathrm{~PB}$ $\mathrm{PT}) /(\mathrm{PF}$ - PT), em que $\mathrm{PB}$ é a produtividade de grãos dos tratamentos com biossólido, PT é a produtividade do tratamento testemunha e PF é a produtividade dos tratamentos com fertilizante mineral.

Tabela 7. Valor da tonelada de biossólido com diferentes teores de água, em razão da quantidade de nitrogênio, fósforo e potássio(1).

\begin{tabular}{ccrcc}
\hline $\begin{array}{c}\text { Teor de água } \\
\left(\mathrm{g} \mathrm{kg}^{-1}\right)\end{array}$ & $\begin{array}{c}\mathrm{N} \\
(\mathrm{R} \$)\end{array}$ & $\begin{array}{c}\mathrm{P} \\
(\mathrm{R} \$)\end{array}$ & $\begin{array}{c}\mathrm{K} \\
(\mathrm{R} \$)\end{array}$ & \multicolumn{1}{c}{$\begin{array}{c}\text { Total } \\
(\mathrm{R} \$)\end{array}$} \\
\hline 900 & 11,37 & 18,48 & 0,59 & 30,44 \\
850 & 17,05 & 27,72 & 0,89 & 45,66 \\
700 & 34,10 & 55,45 & 1,77 & 91,32 \\
500 & 56,84 & 92,41 & 2,95 & 152,20 \\
300 & 79,57 & 129,37 & 4,14 & 213,08 \\
100 & 102,31 & 166,34 & 5,32 & 273,97 \\
\hline
\end{tabular}

${ }^{(1)}$ Os teores de água foram adaptados de Silva et al. (2002b); a análise química do biossólido seco (teor de água $100 \mathrm{~g} \mathrm{~kg}^{-1}$ ) revelou $53,27 \mathrm{~g} \mathrm{~kg}^{-1} \mathrm{de} \mathrm{N} ; 37,37 \mathrm{~g} \mathrm{~kg}^{-1}$ de $\mathrm{P}$ e $3,98 \mathrm{~g} \mathrm{~kg}^{-1}$ de $\mathrm{K}$; os valores da uréia $\left(0,44 \mathrm{~kg} \mathrm{~kg}^{-1}\right.$ de $\left.\mathrm{N}\right)$, do superfosfato triplo $\left(0,184 \mathrm{~kg} \mathrm{~kg}^{-1}\right.$ de $\left.\mathrm{P}\right)$ e do cloreto de potássio $\left(0,498 \mathrm{~kg} \mathrm{~kg}^{-1}\right.$ de $\left.\mathrm{K}\right)$ foram, respectivamente, de $\mathrm{R} \$ 845,00, \mathrm{R} \$ 819,00$ e R\$ 666,00 por tonelada.
No caso de redução da quantidade de água de $900 \mathrm{~g} \mathrm{~kg}^{-1}$ para $500 \mathrm{~g} \mathrm{~kg}^{-1}$ (Silva et al., 2002b), o valor fertilizante do biossólido em NPK seria elevado para $\mathrm{R} \$ 152,20$ por tonelada, um aumento relativo de $400 \%$ (Tabela 7).

Nessas condições, em função da redução do custo relativo de transporte, a relação benefício-custo aumentaria significativamente: o tratamento que recebeu $30 \mathrm{Mg} \mathrm{ha}^{-1}$, se utilizasse o biossólido com teor de água de $500 \mathrm{~g} \mathrm{~kg}^{-1}$, teria sua relação benefício-custo ampliada de 1,15 para 1,61. Portanto, a redução do teor de água do biossólido agrega valor ao produto e pode aumentar seu atrativo de uso pelos agricultores.

\section{Conclusões}

1. O aproveitamento do biossólido como fertilizante na cultura da soja é viável em termos agronômicos e econômicos.

2. O efeito residual do biossólido úmido na soja é evidenciado no segundo cultivo, nas doses acima de $30 \mathrm{Mg} \mathrm{ha}^{-1}$ do material.

3. O biossólido, em média, é 18\% mais eficiente do que o fertilizante mineral como fonte de nutrientes na cultura da soja.

\section{Referências}

BERTON, R.S.; CAMARGO, A.O.; VALADARES, J.M.A.S. Absorção de nutrientes pelo milho em resposta à adição de biossólido a cinco solos paulistas. Revista Brasileira de Ciência do Solo, v.13, p.187-192, 1989.

BRASIL. Ministério das Cidades. Secretaria Nacional de Saneamento Ambiental. Programa de Modernização do Setor Saneamento. Sistema Nacional de Informações sobre Saneamento. Diagnóstico dos serviços de água e esgotos: 2004. Brasília, 2005. 275p. Disponível em: $<$ http://www.snis.gov.br>. Acesso em: 11 jun. 2006.

CANZIANI, J.R.F.; PEGORINI, E.S.; MASSARDO, M.; OSAKI, M. Aspectos socioeconômicos. In: ANDREOLI, C.V.; LARA, A.I.; FERNANDES, F. (Org.). Reciclagem de biossólidos: transformando problemas em soluções. Curitiba: Sanepar, Finep, 2001. p.239-261.

CONAB. Preços da agropecuária. Disponível em: $<$ http:// www.conab.gov.br/acms/clientes/conab/03 publicacoes $>$. Acesso em: 22 maio 2003.

CORRÊA, R.S. Efficiency of five biosolids to supply nitrogen and phosphorus to ryegrass. Pesquisa Agropecuária Brasileira, v.29, p.1133-1139, 2004.

DA ROS, C.O.; AITA, C.; CERETA, C.A.; FRIES, M.R. Lodo de esgoto: efeito imediato no milheto e residual na associação aveiaervilhaca. Revista Brasileira de Ciência do Solo, v.17, p.257$262,1993$. 
EMBRAPA. Centro Nacional de Pesquisa de Solos (Rio de Janeiro, RJ). Manual de métodos de análise de solo. 2.ed. Rio de Janeiro, 1997. 212p. (Documentos, 1).

GADIOLI, J.L.; FORTES NETO, P. Rendimento de milho e de feijão preto cultivado em solo acrescido de lodo de esgoto. Sanare, v.21, p.53-58, 2004.

GUEDES, M.C.; ANDRADE, C.A.; POGGIANI, F.; MATTIAZZO, M.E. Propriedades químicas do solo e nutrição do eucalipto em função da aplicação de lodo de esgoto. Revista Brasileira de Ciência do Solo, v.30, p.267-280, 2006.

IBGE. Censo agropecuário de 1995-1996: utilização das terras do Distrito Federal. Disponível em: $<\mathrm{http} / / \mathrm{www}$.ibge.gov.br $>$. Acesso em: 11 jun. 2006.

LUDUVICE, M. Experiência da Companhia de Saneamento do Distrito Federal na reciclagem agrícola de biossólido. In: BETTIOL, W.; CAMARGO, O. (Ed.). Impacto ambiental do uso agrícola do lodo de esgoto. Jaguariúna: Embrapa Meio Ambiente, 2000. p.153162 .

MACHADO, M.F.S.; FIGUEIREDO, R.F.; CORAUCCI-FILHO, B. Produção brasileira de lodos de esgotos. Sanare, v.22, p.66-74, 2004.

MELO, W.J.; MARQUES, M.O.; MELO, V.P. O uso agrícola do biossólido e as propriedades do solo. In: TSUTIYA, M.T.; COMPARINI, J.B.; ALEM SOBRINHO, P.; HESPANHOL, I.; CARVALHO, P.C.T.; MELFI, A.J.; MELO, W.J.; MARQUES, M.O. (Ed.). Biossólidos na agricultura. 1.ed. São Paulo: Sabesp, 2001. p.289-363.

MELO, W.J.; MARQUES, M.O.; SANTIAGO, G.; CHELLI, R.A.; LEITE, S.A.S. Efeito de doses crescentes de lodo de esgoto sobre frações da matéria orgânica e CTC de um Latossolo cultivado com cana-de-açúcar. Revista Brasileira de Ciência do Solo, v.18, p.449$455,1994$.

MOTTA, R.S. da. Manual para valoração econômica de recursos ambientais. Brasília, Brasil: Ministério do Meio Ambiente, Recursos Hídricos e Amazônia Legal, 1998. 218p. Disponível em: <http:// www.mma.gov.br/port/sbf/chm/publica/mvalora $>$. Acesso em: 15 abr. 2003.

OLIVEIRA, F.C.; MATTIAZZO, M.E.; MARCIANO, C.R.; ROSSETTO, R. Efeitos de aplicações sucessivas de lodo de esgoto em um Latossolo Amarelo distrófico cultivado com cana-de-açúcar: carbono orgânico, condutividade elétrica, pH e CTC. Revista Brasileira de Ciência do Solo, v.26, p.505-519, 2002.

SANEPAR. Manual técnico para utilização agrícola do lodo de esgoto no Paraná. Curitiba, 1997. 96p.

SAS INSTITUTE (Cary, Estados Unidos). The SAS System: release 8.2 (TS2MO) for Windows. Cary, 2001. 1CD-ROM.

SILVA, J.E.; RESCK, D.V.S.; SHARMA, R.D. Alternativa agronômica para o biossólido produzido no Distrito Federal. I. Efeito na produção de milho e na adição de metais pesados em Latossolo no Cerrado. Revista Brasileira de Ciência do Solo, v.26, p.487-495, 2002a.

SILVA, J.E.; RESCK, D.V.S.; SHARMA, R.D. Alternativa agronômica para o biossólido produzido no Distrito Federal. II. Aspectos qualitativos, econômicos e práticos de seu uso. Revista Brasileira de Ciência do Solo, v.26, p.497-503, 2002b.

SOCCOL, V.T.; PAULINO, R.C.; CASTRO, E.A. Metodologia para análise parasitológica em lodo de esgoto. In: ANDREOLI, C.V.; BONNET, B.R.P. (Coord.). Manual de métodos para análises microbiológicas e parasitológicas em reciclagem agrícola de lodo de esgoto. 2.ed. rev. e ampl. Curitiba: Sanepar, 2000. p.27-41. SOUSA, D.M.G. de; LOBATO, E. Adubação com nitrogênio. In: SOUSA, D.M.G. de; LOBATO, E. (Ed.). Cerrado: correção do solo e adubação. Planaltina: Embrapa Cerrados, 2002. p.129-145.

TSUTIYA, M.T. Alternativas de disposição final de biossólidos. In: TSUTIYA, M.T.; COMPARINI, J.B.; ALEM SOBRINHO, P.; HESPANHOL, I.; CARVALHO, P.C.T.; MELFI, A.J.; MELO, W.J.; MARQUES, M.O. (Ed.). Biossólidos na agricultura. 1.ed. São Paulo: Sabesp, 2001. p.133-180.

VARGAS, M.A.T.; MENDES, I.C.; CARVALHO, A.M. de; BURLE, M.L.; HUNGRIA, M. Inoculação de leguminosas e manejo de adubos verdes. In: SOUSA, D.M.G. de; LOBATO, E. (Ed.). Cerrado: correção do solo e adubação. Planaltina: Embrapa Cerrados, 2002. p.97-127.

VIEIRA, R.F.; TANAKA, R.T.; TSAI, S.M.; PÉREZ, D.V.; SILVA, C.M.M. de S. Disponibilidade de nutrientes no solo, qualidade de grãos e produtividade da soja em solo adubado com lodo de esgoto. Pesquisa Agropecuária Brasileira, v.40, p.919-926, 2005. 